\title{
La novela de formación y sus relaciones con la pedagogía y los estudios literarios
}

\author{
Bildungsroman and its relations \\ to pedagogy and literary studies
}

Selen Catalina Arango Rodríguez ${ }^{1}$

\section{Resumen}

El concepto de novela de formación ha tenido diferentes transformaciones como producto de su relación con los estudios literarios. Sin embargo, son pocos los que han abordado los vínculos que el concepto sostiene con la pedagogía y en especial con la formación humana. Esta ausencia señala la necesidad de estudios que, a partir de los estudios literarios y de la pedagogía, encuentren en las novelas de formación nuevos acercamientos para la pregunta abierta acerca de la formación humana, que vayan más allá de una "pedagogización" de la novela.

\section{Palabras clave}

Novela de formación, bildungsroman, pedagogía, formación, estudios literarios.

\section{Abstract}

The concept of bildungsroman has had different transformations as a result of its relation with the literary studies. However, few studies have dealing with the relations of this concept with the field of pedagogy, especially with the human Bildung. This lack shows the necessity of other kind of studies that, linking pedagogy and literary studies, investigate the bildunsroman in order to think human Bildung beyond the simply "pedagogization" of the roman .

Key words:

Novel of formation, bildungsroman, pedagogy, formation, literary studies.

Artículo recibido el 14 de junio de 2009 y aprobado el 16 de octubre de 2009

1 Licenciada en Educación Básica con Énfasis en Humanidades, Lengua Castellana, de la Universidad de Antioquia. Estudiante de segundo semestre de la Maestría en Educación Línea Formación de Maestros de la misma Universidad. En la actualidad, es investigadora del Grupo sobre Formación en Antropología Pedagógica e Histórica, Formaph, Categoría A de Colciencias, de la Facultad de Educación de la Universidad de Antioquia; también es docente de cátedra de esta Facultad y de la Institución Universitaria Tecnológico de Antioquia. Correo electrónico: casimentiras@gmail.com. Agradezco los comentarios hechos por el profesor Andrés Klaus Runge Peña. 


\section{Introducción}

La novela de formación, llamada también bildungsroman (Bellver, 2006; Lee, 2004; Martínez, 2000; Rodríguez, 2000), ha sido denominada en su abordaje clásico como novela de educación o novela de desarrollo del hombre (Bajtín, 2003), como novela pedagógica (Larrosa, 2003), cuando el autor tiene como propósito educar o como novelas sobre educación (Hurtado y Giraldo, 1997) cuando su argumento se centra en el proceso educativo. La novela de formación tiene como variación el kunstleroman o novela de artista.

Es considerada fundamentalmente como género literario (Rodríguez, 1996) o como subgénero de la novela (Castro Lee, 2000) y entendida tradicionalmente como el retrato de un:

Joven de su tiempo que a partir de un feliz estado de ingenuidad, va en busca de almas paralelas, encuentra el amor y la amistad, sostiene conflictos con la dura realidad del mundo hasta llegar a encontrarse consigo mismo, y conocer su propósito en el mundo (Wilhelm Dilthey, 1906, citado por Bellver, 2006).

Otros autores clásicos la nombran como una novela en la que no se da un cambio biográfico en el protagonista:

Sino histórico, es una respuesta al cambio del mundo. [...] La imagen del hombre en el proceso de desarrollo empieza a superar su carácter privado y trasciende hacia una esfera totalmente distinta, hacia el espacio de la existencia histórica. Éste es el último tipo de la novela de desarrollo, el tipo realista (Bajtín, 2003, p. 215)

O como la novela en la que "el protagonista es expuesto a una serie de eventos significativos para su formación personal, y en este proceso toma decisiones que en última instancia no son decisiones suyas sino de los que lo rodean" (Moretti, 2000, reseñado por Lee, 2004).

A partir de la segunda mitad del siglo XX, surgen nuevas maneras de denominarla, entre ellas novela de formación sentimental posmodernista (Ramírez, 2005) y novela de autoformación o novela autoconsciente (Rodríguez, 1996). Se comienza a hacer referencia en la teoría literaria a una novela de formación femenina, ya sea como novela de concienciación (Ciplijauskaité, 1988) o manteniendo su denominación alemana, bildungsroman femenino (Castro, 2000; Allende, 2000).

A pesar de su transformación en los textos que aquí se reseñan -para referirse al concepto de novela de formación- el libro clásico del género: el Wilhelm Maisters Lehrjahre de Goethe y el establecimiento del concepto de novela de formación con Wilhem Dilthey (Bellver, 2006, p.103; Castro, 2000, p.356). El libro más citado (en Bellver, 2006; Lee, 2004; Martínez, 2000) para abordar el concepto de novela de formación es The Way of the World (2000) en la que Franco Moretti se dedica a hacer un panorama de la novela de formación en la cultura europea.

\section{Abordajes de la novela de formación en los estudios literarios}

Los estudios literarios se ocupan de la creación literaria en la que el lenguaje construye "mundos imaginarios que nos aproximan a múltiples posibilidades de conocer, comprender, expresar, comunicar la realidad y nos orientan en la búsqueda de sentidos para la existencia personal y la vida comunitaria" (Importancia y sentido de los estudios literarios, 2006). Forman parte de los estudios literarios la teoría, la crítica y la historia literaria.

En el contexto de estos estudios, la novela de formación es considerada como un subgénero de la novela que se clasifica en otros subgéneros, según el tipo de héroe y el movimiento literario al que se inscriba la novela. Así, la novela de formación se nutre del realismo (Bajtín, 2003; Lee, 2004), del modernismo (Bohórquez, 2005) y del posmodernismo (Ramírez, 2005). Es más, Franco Morreti, desde la teoría de la narración y desde una historia social, en su libro The way of the world, inscribe la bildungsroman como el género paradigmático de la modernidad:

Entendida como la consolidación europea del modelo capitalista burgués y la transformación de las sociedades tradicionales bajo el empuje de los ideales ilustrados de razón, progreso y bienestar social. La experiencia de aprendizaje que se retrata en este tipo de novelas representaría, por lo tanto, 
la paulatina interiorización y legitimación de los valores propios de un nuevo orden social burgués (Moretti 1987, citado por Bellver, 2006).

\section{La teoría literaria}

La teoría literaria es aquí asumida como un campo conceptual que, por medio de la indagación, se dedica a proponer lentes o puntos de observación del hecho literario. Es así como, además de entregar diferentes tipos de respuestas a la pregunta ¿qué es la literatura? y de considerar que este interrogante no tiene solución, toda definición es provisoria y relativa (Eagleton, 2002). Las definiciones se han dedicado a construir elementos teóricos, categorías y criterios para dirigir y fundamentar estudios (Maldonado, 2006, p.10) que pongan en diálogo los elementos relacionados con la creación literaria: autor, lector, texto y contexto.

Desde esta perspectiva, la novela de formación es un objeto de investigación interesante para un trabajo que se dedique a considerar sus características generales luego de analizar un grupo de novelas de formación. A su vez, este tipo de trabajos se pueden inscribir en una de las corrientes de la teoría literaria, las cuales son: el formalismo, el estructuralismo, el psicoanálisis, el marxismo, postestructuralismo, deconstrucción y posmodernismo, el feminismo, los estudios de género, teoría queer y de perspectiva homosexual, el historicismo y los estudios étnicos, postcoloniales e internacionales (Ryan, 1999). Los trabajos desarrollados en esta perspectiva acerca de la novela de formación son: Bajtín (2003) La novela de educación y su importancia en la historia del realismo, y, para el caso que nos ocupa en este artículo, el libro Aproximaciones teóricas al concepto del bildungsroman femenino, de Luiselli Allende Buitrago (2000).

Algunas de las novelas de desarrollo del hombre estudiadas por Bajtín se relacionan en que tienen un carácter esencialmente autobiográfico o biográfico; en unas, el principio organizador es la idea puramente pedagógica acerca de la formación de un hombre, mientras que otras no la contienen en absoluto; unas se estructuran por el orden cronológico del desarrollo y educación del protagonista y carecen casi de argumento, y otras, por el contrario, poseen un complicado argumento lleno de aventuras. Para Bajtín, las diferencias que tienen que ver con la re- lación que existe entre estas novelas y el realismo, y particularmente con el tiempo histórico real, son aún más considerables.

Para delimitar la novela de desarrollo de tipo realista, Bajtín estudió la función del héroe en las novelas. Encontró que hay unas novelas en las que se da una traslación del héroe en el espacio por medio de la escala de la jerarquía social: va de vagabundo a rico; o bien puede alejarse o acercarse a su destino: la novia, el triunfo, la riqueza; y que en ellas, el héroe es una constante que no cambia: "Los acontecimientos truecan su destino, cambian su posición en la vida y en la sociedad, pero el héroe mismo permanece sin cambios, igual a sí mismo" (Bajtín, 2003, p. 211). Todo puede cambiar, el ambiente, la posición social, lo que lo rodea es variable pero él no porque es un punto rodeado por elementos que cambian. En contraste con las novelas mencionadas, en las novelas de formación, el héroe cambia, es más, él mismo y su carácter llegan a ser una variable dentro de la fórmula de la novela:

La transformación del propio héroe adquiere una importancia para el argumento de la novela. El tiempo penetra en el interior del hombre, forma parte de su imagen cambiando considerablemente la importancia de todos los momentos de su vida y su destino. Este tipo de novela puede ser denominado en un sentido muy general, novela de desarrollo del hombre (p. 212).

Si bien Bajtín en su texto La novela de educación y su importancia en la historia del realismo ubica las diferentes modalidades de la novela de desarrollo, la concepción de un individuo histórico, que permite una concienciación en relación con la época, no da cuenta de una transformación interna del protagonista de la novela. Es decir, que además de una ubicación en el mundo y en sus circunstancias, el héroe debe también atravesar un camino hacia sí mismo por medio de ese mundo. Pedagógicamente hablando, a esta perspectiva, le hace falta considerar que además de ubicarnos en el mundo son las experiencias que éste nos propone, las que nos llevan a considerarnos o no como sujetos históricos. Posiblemente, existan novelas de formación en las que sus protagonistas no quieran inscribirse como históricos y pasen de largo ante lo que sucede en 
su sociedad. Según Gómez (2002), en el Wilhem Meister, publicada en 1796 por Goethe, en ningún momento se mencionan los acontecimientos históricos que rodean al protagonista, pues su figura es el correlato de la identidad nacional alemana de la época: burgués y de frágil carácter psicológico; de ahí que este personaje no debía ser un hombre histórico y, como consecuencia, su relato fue un anacronismo de un joven cándido que

Recorre una Alemania suspendida de la historia, como libre de conmociones mayores; una Alemania entretenida en juegos más bien inocentones, en un ideal de superación por vía de una formación vitalista integral de innegable fuerza simbólica (2002, pp. 49-51).

Una teoría literaria acerca de la novela de formación debe preguntarse por el concepto de formación y considerarlo no desde su acepción clásica (el proceso para ascender a una sociedad burguesa), sino por las maneras en las que llegó el protagonista a preguntarse por lo que es, pregunta, que lleve a analizar las experiencias no sólo de formación sino también de transformación y de deformación.

\section{La crítica literaria}

Se define esencialmente como una aproximación o lectura más o menos rigurosa de una obra o período de la literatura. La crítica es sin duda la más subjetiva de las reflexiones sobre la literatura $y$, en consecuencia, la que con mayor insistencia está subordinada a las consideraciones sociales y sus derivadas formas (Importancia y sentido de los estudios literarios, 2006).

Es un estudio sincrónico de obras y fenómenos literarios concretos (Maldonado, 2006) que, para el caso de este artículo, va tener como ejemplo la manera como ha sido estudiada una modalidad de la novela de formación: la novela de formación femenina.

La crítica literaria asume el análisis de la novela de formación y de la novela de formación femenina en relación con los denominados movimientos literarios: el realismo (Bajtín, 2003; Lee, 2004), el modernismo (Bohórquez, 2005) y el posmodernismo (Ramírez, 2005).

Otro tipo de acercamiento a la novela de formación femenina es el de Castro Lee (2000), quien la propone como un subgénero de la novela que se diferencia del bildungsroman clásico por cuanto es flexible y maleable para abarcar el despertar de la conciencia de la protagonista y el de Ciplijauskaité (1988), quien la denomina como novela de concienciación. Este abordaje se relaciona con el de Castro Lee (2000) al mencionar que este tipo de novela da cuenta del desarrollo de la conciencia de la mujer y que son diferentes las estrategias narrativas femeninas de las masculinas.

Veamos, entonces, las anteriores propuestas para el abordaje de una novela de formación y de una novela de formación femenina:

Sohyun Lee (2004), en su artículo El Bildungsroman y el realismo: la mujer como agente del libre albedrío en Pepita Jiménez de Juan Valera, luego de definir los conceptos de novela realista español ${ }^{2}$ y de novela de formación, procede al análisis de la novela en clave de bildungsroman clásico, el cual considera como una novela que se refiere al desarrollo de un joven en un espacio de tiempo determinado, haciendo factores determinantes del género como son la vocación, dudas o decisiones, así como la eventual asimilación del joven a la sociedad luego de despojarlo "de una libertad plena y una voluntad enérgica (Lee, 2004, p. 121).

Para llegar a lo anterior, la autora observa las acciones del personaje masculino de la novela, Don Luis, siguiendo la propuesta del Bildungsroman clásico en la que, según Lee (2004), las decisiones que toman los personajes de este tipo de novelas son, en realidad, las decisiones de los que los rodean. El héroe de la Bildungsroman clásica opta por lo que otros desean y desiste de sus deseos menores porque no puede tener las dos cosas a la vez. En este tipo de novela los personajes no tienen opción al libre albeldrío.

2 Para Sohyun Lee (2004), la tradición europea realista mantiene sujetos a sus personajes a la tradición y a sus experiencias pasadas, mientras que en la española se le entrega gran importancia al libre albedrío como sucede con la novela Pepita Jiménez. 
A diferencia del personaje principal, Pepita Jiménez va en contra del bildungsroman clásico. Primero porque es mujer, y el género en su denominación clásica sólo admite como héroes a los varones. Además es viuda, situación que permite reconocer dificultades en su socialización, proceso que apenas emprendería un héroe del género clásico. Por último, ella es la que decide conquistar a Luis, el héroe de la novela. Pepita es un "personaje de carácter fuerte y voluntad propia, como son la mayoría de los personajes femeninos de la novela del siglo XIX" (Lee, 2004, p. 127).

Si el personaje femenino de Valera, Pepita Jiménez, a finales del siglo XIX en España se diferencia de los héroes de la Bildungsroman clásica, transgrediendo la tradición realista en la que se espera que se mantengan las tradiciones, en Venezuela, Douglas Bohórquez (2005) considera que la novela de formación permitió en su nación marcar la transición de una novela realista a una moderna.

En su texto Novela de formación y formación de la novela en los inicios del siglo XX en Venezuela, Douglas Bohórquez (2005) a partir del análisis de tres novelas de José Gil Fortouol, Manuel Díaz Rodríguez, Rómulo Gallegos y Teresa de la Parra, da cuenta tanto del proceso de constitución formal de la novela venezolana y del proceso histórico de la novela de formación en Venezuela. Además de esto, alude a que si se observa la relación entre novela de formación e inicios de la modernidad, ésta podría mirarse no sólo en Venezuela, sino también en otros países hispanoamericanos para ubicar las problemáticas relacionadas con la modernidad de inicios del siglo XX (el surgimiento de las empresas, la influencia de Europa en la cultura de los países latinoamericanos) que llevaron a un cambio en sus narrativas, provocado directamente por el influjo de este movimiento y la necesidad de encontrar en los modelos europeos posibles formas de ser.

A partir del análisis de las novelas, el autor llega a considerar que la asimilación de la modernidad en los países hispanos se relaciona con los procesos de migración de sus escritores a Europa. Una de las características de las novelas analizadas por Bohórquez es aquella según la cual sus personajes deciden irse de su Venezuela en busca de la cultura europea, viaje que los lleva a extrañar aún más a su tierra y lo que realmente eran. Esta relación, la búsqueda de ideales modernos y la novela de formación, permitiría considerar la ambivalencia que genera el tratar de encontrar nuevas formas de ser que no se relacionan justamente con lo que se es, pero que su búsqueda de quien lo hace, lo lleva a valorarse y a enunciarse desde su propio discurso.

Para Bohórquez, la consolidación de la novela moderna en Venezuela se relaciona con el influjo de la modernidad y con ella la novela de formación. Esto permite considerar una nueva perspectiva que avanza de la primera mitad del siglo veinte a su final: la novela de formación como posibilidad para nuevas narrativas posmodernas en las que ya no se trata de narrar la consolidación de la modernidad sino de un cuestionamiento de la misma.

A la vertiente de la crítica literaria que analiza la novela posmoderna pertenece el texto de Rebeca Ramírez (2005), La nueva novela de formación sentimental posmodernista, en la que se analiza Los impacientes (ganadora del Premio Biblioteca Breve en 2000) del escritor argentino Gonzalo Garcés. Esta novela se aleja del modelo tradicional de la bildungsroman y de la novela sentimental y muestra un nuevo tipo de novela formación sentimental posmodernista, caracterizado por la relatividad del proceso de formación.

La autora comienza definiendo el concepto de novela posmodernista, la cual presenta en su interior una diversidad de géneros y de fragmentos de otros textos literarios existentes o no. Juegos que exigen la presencia de un lector inteligente con un buen bagaje cultural por cuanto cada novela posmodernista lo lleva a una rica intertextualidad. En el contexto de estas novelas, la autora ubica la de Gonzalo Garcés para decir que se caracteriza por la relatividad del proceso de formación y por la incertidumbre del narrador. Este tipo de novelas, según la autora, inicia en los años setenta, cuando la narrativa empieza a mostrar el desencanto de la humanidad y del escritor, quien se vuelve sobre sí para olvidarse de la colectividad. En las novelas sentimentales, los personajes tienen la posibilidad de enfrentarse a los discursos hegemónicos que le han quitado su individualidad. En la novela de formación sentimental posmodernista, el proceso de formación sentimental nunca acaba y alcanzar la madurez es una aspiración que podría satisfacerse por un instante. 
En el contexto colombiano, y también considerando la relación novela de formación y posmodernidad, se encuentra el artículo de Juan Guillermo Gómez (1998) denominado Garabato, ¿Una novela de formación?, en el que el concepto de novela de formación clásico, aquel que se relaciona con el ascenso a una clase burguesa, es visto desde el otro lado por el narrador: desde lo patético y lo inesperado. En Garabato (1939), de Antonio Osorio Lizarazo, se narra cómo su personaje, un joven alumno del Colegio Nacional de los Jesuitas, Juan Manuel Vásquez, termina viendo sus ilusiones desfallecerse. Su final, desastroso y patético, indigna al lector. Según Gómez, las novelas de Lizarazo van en contra de los ideales modernos y se contraponen a la novela de formación de la literatura burguesa europea, que en su período clásico se pregunta por el problema de la integración del individuo en la sociedad, y que encuentra en las "novelas de formación" su expresión más características; aquí Gómez (1998) cita a novelas como el Wilhelm Meister de Goethe, La guerra y la paz de León Tolstoi o El amigo Manso de Pérez Galdós.

En las novelas de Lizarazo, este problema se define por su ausencia misma:

Los aspectos básicos de esa compleja integración y la adaptación son en Garabato reducidos a esa dulce filosofía mediocre del carpintero Juan Manuel -ya en el "Prólogo" - aislado, contemplativo, inerme e indiferente, incluso ante esa sociedad dominada por un feroz egoísmo y un fanatismo idiota a la que debe su marginalidad (Gómez, 1998, p. 48).

En general, esta perspectiva permite ubicar problemas que deberían tenerse en cuenta para un estudio acerca de las novelas de formación: el artículo de Bohórquez (2005) presenta las novelas de formación, objeto de su análisis, como los inicios del modernismo en la narrativa moderna venezolana. Relación que lleva a considerar las novelas de formación como un proyecto que se relaciona con los ideales de hombre y de mujer a formar en un país, por cuanto dan cuenta de la "evolución del género de la novela” (Bohórquez, 2005) por medio de formas que corresponden con los cánones europeos. Es decir, se encuentra aquí una asimilación del modelo europeo narrativo, influencia que el mismo Bohórquez cuestiona en el análisis de los personajes de las novelas que desean lo extranjero antes que lo nacional. Esto lleva a ubicar como otra categoría a tener en cuenta en el análisis de las novelas de formación esta problemática por cuanto la familia, el estado, la educación, las diferentes religiones, tienen en mente un ideal a formar. La problemática por resolver para los personajes de las novelas de formación sería elegir qué es lo que realmente quieren ser en relación con sus intereses y al de los otros que lo forman.

Sin embargo, esta misma asimilación lleva a la siguiente pregunta: ¿es la novela de formación, necesariamente, la encargada de mantener los ideales nacionales? Posiblemente esta pregunta encontraría su respuesta en que, evidentemente, la literatura da cuenta de las realidades en las que se encuentra su autor. Realidades que, para el caso del texto, se encuentran en la necesidad de difundir en todos los medios posibles lo que significa la nación, para el caso de Bohórquez (2005), venezolana. Pero esta pregunta también lleva a ahondar en lo que el artículo de Bohórquez no menciona: la relación que tendrían las novelas de formación con la pedagogía en un concepto más amplio que no la ubique sólo en la escuela, sino en los procesos y experiencias que también forman al ser humano en su vida.

A diferencia de la perspectiva tradicional de un concepto de formación, Ramírez (2005) y Gómez (1998), con la presentación de una novela de formación sentimental posmoderna y de una posibilidad de procesos formativos no exitosos, respectivamente, señalan la necesidad de considerar la formación no como una línea, sino como red de hilos que pueden llevar a ningún lugar o al fracaso. Lo anterior se une a la perspectiva que Lee (2004) abre en su texto: la de una novela de formación femenina, sobre todo, cuando ésta puede considerar que los procesos formativos de las mujeres son diferentes al de los hombres, pues Pepita era una mujer viuda en una sociedad que ya la veía soltera el resto de su vida, mientras que Juan era un hombre soltero que podía enamorarse de la viuda.

De esta manera, los textos abordados que corresponden a una crítica literaria llaman la atención a los análisis pedagógicos de las novelas de formación y les solicitan no hacer grandes teorías acerca de 
la formación (como sucede con algunos textos de teoría literaria ya revisados), sino una búsqueda de novelas esenciales en una determinada época que sobresalen por su manera de abordar las problemáticas relacionadas con la formación humana. Aún más, la crítica literaria permitiría considerar un análisis de novelas de formación femenina para caracterizarlas como una nueva tendencia que en la actualidad debe comenzar a configurarse como un campo de investigación en la pedagogía, respondiendo a una de las características de la novela escrita por las mujeres a partir de la segunda mitad del siglo XX: la autoconcienciación (Ciplijauskaité, 1988).

\section{La necesidad de estudios de las novelas de formación desde una perspectiva pedagógica}

En un análisis pedagógico de las novelas de formación debe importar más lo relacionado con el proceso autoformativo humano y no tanto la posibilidad autoformativa que la novela provoca en sus lectores, como propone Rodríguez (1996) al decir que "la autoformación", representada en la sintaxis de la historia narrada, no hace más que poner de relieve lo que implica la misma pragmática literaria: "se autoforma el héroe o protagonista en la historia ficticia; pero el autor y el lector de la novela dejan de ser inocentes con esta experiencia. También ellos, como el personaje, se autoforman" (Rodríguez, $1996,26)$. Se trata de no afirmar que los lectores de una novela de formación se forman por medio de ellas, sino de considerar que la lectura puede

\section{Bibliografía}

Bajtín, M. (2003). La novela de educación y su importancia en la historia del realismo. En Estética de la creación verbal (pp. 200-248). México: Siglo XXI Editores.

Bellver Sáez, P. (2006). El Bildungsroman y la aparición de un espacio puertorriqueño en la literatura de los EEUU. Atlantis. 1(28), 101-113. Extraído el 26 de marzo de 2008 desde www.atlantisjournal.org/ Papers/28_1/P.Bellver.pdf

Bohórquez, D. (2005). Novela de formación y formación de la novela en los inicios del siglo XX en Venezuela. Cuadernos de Cilha, 7-8. Extraído el 15 de febrero aportar a ese proceso pero nada garantiza que quien lea una novela sea mejor o peor: "Todo indica que el ser humano que lee, si bien es un hombre culto, en promedio no es más pacífico que el que no lee" (Pöppel, 2004, p. 115).

Se trata de no seguir proponiendo la literatura, en especial la infantil y la juvenil, como una herramienta para transmitir valores vigentes. Se trata de rescatar la literatura, y con ella las novelas de formación, de la pedagogización a la que está siendo sometida:

La literatura es peligrosa porque actúa sobre los lectores justamente en sentido contrario que cualquier modalidad de transmisión de un "deber ser" consensuado socialmente. La literatura es búsqueda y descubrimiento de significados, y no reproducción pasiva de verdades digeridas por otros. Como el juego, el arte en general, la literatura es gratuita, inútil, indomesticable (Carranza, 2006).

Así las cosas, proponer la relación: pedagogía y literatura como línea de indagación para la investigación en pedagogía, implica no entender las novelas de formación como textos para enseñar algo, como un conjunto de libros que pueden ser utilizados en las aulas de clase con el propósito de que los y las estudiantes encuentren una enseñanza para sus vidas, sino como fuentes primarias para un estudio pedagógico e histórico acerca de la formación humana.ฏ

de 2008 desde http://bdigital.uncu.edu.ar/bdigital/ fichas.php?idobjeto $=1106$

Carranza, M. (2006). La literatura al servicio de los valores, o cómo conjurar el peligro de la literatura. Imaginaria. Revista quincenal sobre literatura infantil y juvenil, 181. Extraído el 9 de julio de 2008 desde http://www.imaginaria.com.ar/18/1/literatura-yvalores.htm

Castro Lee, C. (2000). La novela de formación en la narrativa de Rocío Vélez, Ketty Cuello, Silvia Galvis y Consuelo Triviño. En: M. M. Jaramillo, B. Osorio y A. Robledo (ed.), Literatura y cultura. Narrativa 
colombiana del Siglo XX. Volumen III. Hibridez y alteridades (Vol. III, pp. 356-391). Bogotá: Ministerio de Cultura.

Ciplijauskaité, B. (1988). La novela femenina contemporánea (1970-1985). Hacia una tipología de la narración en primera persona. España: Anthropos.

Eagleton, T. (2002). Una introducción a la teoría literaria. México: Fondo de Cultura Económica.

Gómez García, J. (1998). Garabato, ¿Una novela de formación?. Estudios de Literatura Colombiana, 2, 41-52.

Gómez García, J. (2002). Sobre el concepto de formación en el Wilhelm Meister de Goethe. Revista Educación y Pedagogía, 32(XIV), 41-51.

Lee, S. (2004). El Bildungsroman y el realismo: la mujer como agente del libre albedrío en Pepita Jiménez de Juan Valera. Divergencias. Revista de Estudios Lingüísticos y Literarios, 2, 119-128. Extraído el 14 de abril de 2008 desde www.coh.arizona.edu/divergencias/archives/spring2004/Pepita.pdf

Maldonado, M. (2006). La historiografía literaria. Una aproximación sistémica. Revista de Filología Alema- na, 14, 9-40. Extraído el 12 de mayo de 2008 desde http://www.ucm.es/BUCM/revistas/fll/11330406/ articulos/RFAL0606110009A.PDF

Pöppel, H. (2004). ¿Enseñar literatura?. En Literatura y educación. La literatura como instrumento pedagógico (pp. 109-131). Medellín: Comfama.

Ramírez Hernández, R. (2005). La nueva novela de formación sentimental posmodernista. Revista de Filología y Lingüística de la Universidad de Costa Rica, 1(XXXI), 101-113. Extraído el 13 de marzo de 2008 desde www.latindex.ucr.ac.cr/descargador. php?archivo=rfl001-05

Revista de la Facultad de Filosofía y Humanidades. (s. f.). Importancia y sentido de los estudios literarios y lingüísticos. Cyber Humanitatis, 38. Extraído el el 16 de junio de 2008 desde http://www.cyberhumanitatis.uchile.cl/CDA/vida_simple3/0,1251,SCID\%253 D18490\%2526ISID\%253D646,00.html

Ryan, M. (2002). Teoría literaria: una introducción práctica. España: Alianza Editorial. 